\title{
Immunization with MHC class I-negative but not -positive HPV16-associated tumour cells inhibits growth of MHC class I-negative tumours
}

\author{
MILAN REINIS, JANA SÍMOVÁ, MARIE INDROVÁ, JANA BIEBLOVÁ, HANA PRIBYLOVÁ, \\ SIMONA MORAVCOVÁ, TÁNA JANDLOVÁ and JAN BUBENÍK \\ Institute of Molecular Genetics, Academy of Sciences of the Czech Republic, Prague, Czech Republic
}

Received October 26, 2006; Accepted December 22, 2006

\begin{abstract}
Loss or downregulation of MHC class I molecules on tumour cells is a common mechanism by which tumours can escape from T-cell mediated immune responses. In this study we have investigated the immunologic crossreactivity between murine tumour cell lines expressing human papilloma virus (HPV) 16-derived E6/E7 oncoproteins with distinct surface expression of MHC class I molecules. The aims of this study were to demonstrate whether immune responses capable of coping with MHC class I-positive tumours can also be effective against their MHC class I-deficient derivatives and whether it is possible to induce immunity against MHC class I-deficient tumours by cellular vaccines based on MHC class I-deficient tumour cell lines. Our data showed that immunization with MHC class I-deficient but not with MHC class I positive tumour cells inhibited the growth of MHC class I-deficient tumours. In vivo depletion studies revealed that the mechanisms underlying effective immune responses against MHC class I-negative tumours in animals immunized with MHC class I-deficient tumour cells involved natural killer cells. The presented findings are of particular clinical relevance in the sense of construction of vaccines directed against a broad spectrum of HPV-associated tumours.
\end{abstract}

Correspondence to: Professor Jan Bubeník, Institute of Molecular Genetics, Academy of Sciences of the Czech Republic, Videnska 1083, 142 20, Prague 4, Czech Republic

E-mail: bubenik@img.cas.cz

Abbreviations: HPV, human papilloma virus; $\mathrm{T}_{\text {reg }}$ cells, $\mathrm{T}$-regulatory cells; CTL, cytotoxic T lymphocyte; Th, T helper lymphocyte; NK, natural killer; MK16 cells, MK16/1/IIIABC cells; MFI, mean fluorescent intensity; E/T, effector/target cell ratio; TAP, transporter associated with antigen processing; LMP, low-molecular mass polypeptide

Key words: HPV16, MHC class I-deficient tumours, immunologic crossreactions, anti-tumour vaccines

\section{Introduction}

One of the major problems in the search for effective anticancer vaccines is the development of vaccines that could be used against a broad spectrum of tumours belonging to the same histological type, but originating from different patients or against tumours at different stages of their development. Partial and total loss of the MHC class I expression on tumour cells are frequent events in the course of tumour development, including cervical carcinoma (1-4). MHC class I downmodulation is considered to be one of the principal mechanisms of tumour escape from the immune surveillance mediated by cytotoxic T lymphocytes (CTLs) (5-8). On the other hand, complete loss of MHC class I surface expression on tumour cells makes them susceptible to the lysis mediated by natural killer (NK) cells due to 'missing self' recognition $(9,10)$. This NK-mediated immune response is considered to be weaker than the CTL-mediated responses, although this conclusion is not universal $(11,12)$.

A question is whether it is possible to induce immunity against MHC class I-deficient tumours by immunization with cellular vaccines and whether such vaccines would be active exclusively against MHC class I-negative tumours (13). Another important factor in understanding the mechanisms of the tumour escape from immune surveillance is the efficacy of the possible MHC class I-unrestricted immune responses elicited by MHC class I-positive tumour cells against MHC class I-deficient tumour derivatives.

It is known that MHC class I-deficient tumours can be effectively controlled by the immune system $(13,14)$ and that they are susceptible to immunotherapeutic intervention with cytokines (15), unmethylated CpG oligonucleotides (16) or cellular vaccines based on tumour cells engineered to express immunoactive molecules $(17,18)$. The mechanisms underlying immunocytokine therapy can differ according to the level of MHC class I expression on tumour cells (19). The effects of specific vaccinations are much less understood. So far, the results of the limited number of studies using well-defined experimental tumours in respect to their MHC class I status indicate that it is possible to induce effective immunity against MHC class I-deficient tumours at least with immunization protocols using cytokines or costimulatory molecules as adjuvants $(17,20-23)$. The mechanisms underlying this 
immunity are not fully understood; they may include for example NK, Th cells and IFN $\gamma$ production $(21,24)$. In addition, the role of $\mathrm{CD}^{+}$cells cannot be excluded (25). The specificity of immunization protocols may be questionable as protective immunity, e.g. after DNA immunization, was achieved also with control vectors (24). More studies on the differences in immune responses against tumours of the same aetiology, but different in expression of MHC class I molecules, as well as experiments focused on immunologic crossreactivity between parental tumour cells and their MHC class I-deficient derivatives are required.

Most cervical neoplasms can be attributed to infection with high-risk human papilloma virus (HPV), HPV16 and HPV18 being the most prevalent types. Viral oncoproteins E6 and E7 are expressed in all tumour cells and crucial for maintaining a malignant phenotype. Therefore, they have been selected as targets of choice for specific immunotherapy promoting the response against HPV-associated tumours. Several MHC class I-deficient sublines derived from model murine tumour cell lines expressing E6/E7 viral oncogenes have been established and characterized (26).

Preliminary data from our laboratory revealed that two distinct cell lines TC-1 (MHC class I-positive) and MK16/1/ IIIABC (MK16, MHC class I-negative) expressing E6/E7 antigens did not immunologically crossreact in vivo (27). In this study, we have analyzed the immune crossreactivity between parental tumour cells and their immune escape variants, expressing E6/E7 antigens but deficient in their MHC class I expression. Moreover, we have investigated the crossreactivity between two distinct MHC class I-deficient tumour cell lines expressing the same E6/E7 oncoproteins. We have used a model of tumour cells with MHC class I down-modulation due to defects in APM. This model is of clinical relevance since the MHC class I-deficient tumour derivatives originating from coordinated downregulation of APM components $(28,29)$ are frequently observed in HPVassociated cervical carcinomas in humans $(30,31)$.

\section{Materials and methods}

Cell lines. Moderately immunogenic MHC class I-positive cell line TC-1 was obtained by in vitro co-transfection of murine lung C57BL/6 cells with HPV16 E6/E7 and activated human Ha-ras (G12V) oncogenes (32). TC-1/A9 (MHC class I-negative) (33) and TC-1/P3C10 (with reduced expression of MHC class I molecules) (21) cell lines represent tumour cell derivatives which escaped from the selection pressure mediated by the specific immune response due to concomitant tumour immune response since they were obtained from TC-1 tumours developed in immunized mice. Another E6/E7expressing MHC class I-deficient cell line MK16, moderately immunogenic in syngeneic mice derived from kidney C57BL/6 cells, was described in detail elsewhere (34). MHC class I downmodulation in all cell lines was caused by defects in expression of genes of antigen-presenting machinery (TAP-1, TAP-2, LMP-2, LMP-7). The RVP3 cell line (35) has been used as an indifferent MHC class I-deficient control, not associated with HPV16. All cell lines were cultured in RPMI1640 medium supplemented with $10 \%$ of foetal calf serum, L-glutamine and antibiotics.
Mice. C57BL/6 (B6) mice, 2-4 months old, were obtained from Anlab, Prague, Czech Republic. The mice were housed in the animal facility of the Institute of Molecular Genetics. Experimental protocols were approved by the Institutional Animal Care Committee of the Institute of Molecular Genetics, Prague.

In vivo immunization-challenge experiments. Mice were twice immunized with $1 \times 10^{7}$ irradiated tumour cells (days -35 and -14 , subcutaneous injection, irradiation dose $150 \mathrm{~Gy}$ ) and challenged on day 0 . All tumour cells were injected subcutaneously. The experimental and control mice were observed bi-weekly, and the numbers of tumour-bearing mice and the size of the tumours were recorded. Two perpendicular diameters of the tumours were measured with a calliper and the tumour size was expressed as the tumour area $\left(\mathrm{cm}^{2}\right)$.

Peptides and peptide immunization. The HPV16-derived, high affinity $\mathrm{H}-2 \mathrm{D}^{\mathrm{b}}$ binding peptide $\mathrm{E}_{49-57}$ (RAHYNIVTF) (36) and the control peptide, $\mathrm{H}-2 \mathrm{~K}^{\mathrm{b}}$ binding, ovalbumin-derived $\mathrm{OVA}_{257-264}$ (SIINFEKL), both of them CTL epitopes, were synthesized at the Institute of Organic Chemistry and Biochemistry, AS CR, Prague, or custom-synthesized by Sigma Genosys (Cambridge, UK). For immunizations, peptides were s.c. injected 25 days and 11 days prior to the challenge with tumour cells. Unmethylated $\mathrm{CpG}$ oligodeoxynucleotide 1826 (CpG ODN 1826) (37) was used as an adjuvant. The dosage for immunization was $100 \mu \mathrm{g}$ peptide and $50 \mu \mathrm{g} \mathrm{CpG}$ ODN 1826 in $150 \mu 1$ PBS per dose.

Flow cytometry. Cell surface expression of MHC class I $\left(\mathrm{H}-2 \mathrm{~K}^{\mathrm{b}} / \mathrm{H}-2 \mathrm{D}^{\mathrm{b}}\right), \mathrm{CD} 80, \mathrm{CD} 86$ and CD54 on the cell lines was determined by cytofluorometric analysis using anti-mouse monoclonal antibodies: PE hamster IgG1 $\lambda 1$ isotype control, PE anti-H-2D ${ }^{\mathrm{b}}$ (KH95), PE anti-H-2K ${ }^{\mathrm{b}}$ (AF-88.5), PE antiCD80 (B7-1) (16-10A1), PE anti-CD54 (ICAM-1) (3E2), FITC rat $\mathrm{IgG}_{2 \mathrm{a}} \kappa$ isotype standard, PE anti-CD86 (GL1), FITC anti-I- $^{\mathrm{b}}\left(\mathrm{A} \mathrm{B}^{\mathrm{b}}\right)(\mathrm{AF} 6-120.1)$, purified anti-mouse Qa- ${ }^{\mathrm{b}}$ (6A8.6F10.1A6) and FITC-conjugated goat anti-mouse Ig antibody. Cells were preincubated with anti-CD16/CD32 antibody to minimize non-specific binding and the analysis was performed using a FACScan Elite cytometer (Coulter, Miami, FL). For analysis, 10,000 cells were counted. All antibodies utilized including the isotype-matching controls were purchased from Pharmingen, San Diego, CA.

$R T$-PCR. Total RNAs were isolated from cell lines using the RNA isolation kit (Roche, Indianapolis, IN) according to the manufacturer's instructions. Oligo (dT)-primed reverse transcription was performed with GeneAmp RNA Core Kit (Applied Biosystems, Foster City, CA). cDNAs were amplified by PCR using the same kit and specific primers for ß-actin, H-2D ${ }^{\mathrm{b}}, \mathrm{H}-2 \mathrm{~K}^{\mathrm{b}}$, TAP-1, LMP-2, HPV16 E6, HPV16 E7 $(33,34)$, TAP-2 (38), LMP-7 (28), B7-H1 and B7-H2 (39).

Determination of the relationship between the levels of MHC class I expression on tumour cells and their sensitivity to lysis by spleen cells from immunized mice. MHC class I expression on TC-1/A9 or MK16 cells was induced by culturing for $72 \mathrm{~h}$ in 
a/

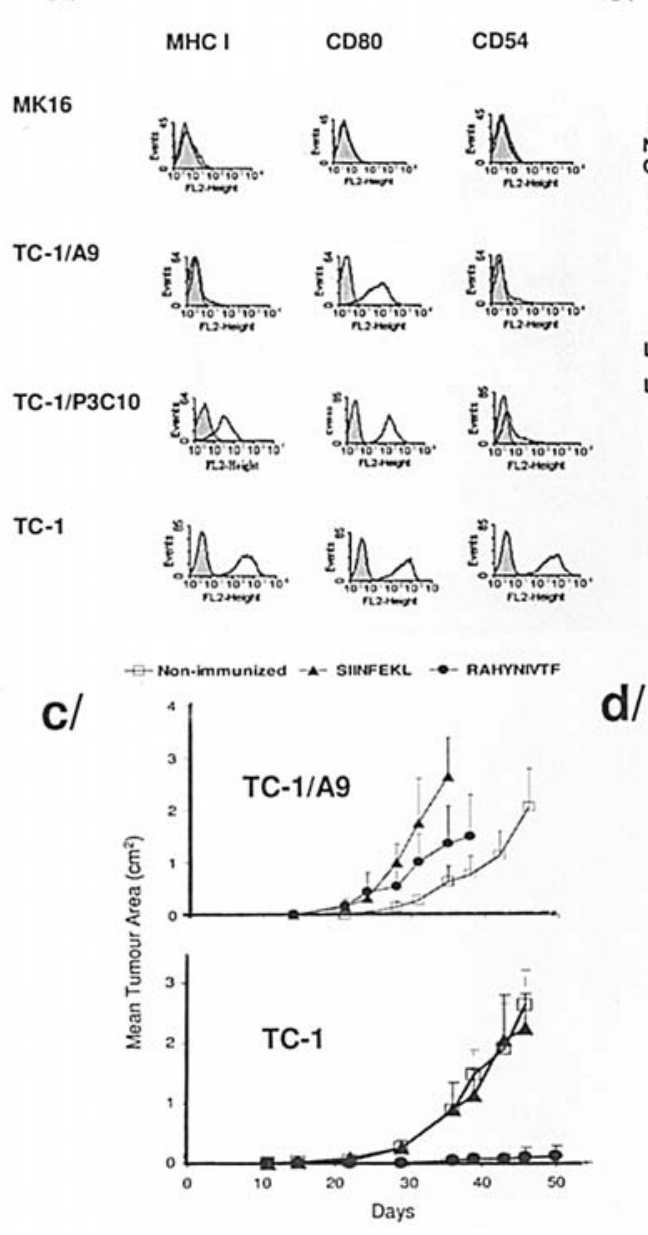

b/

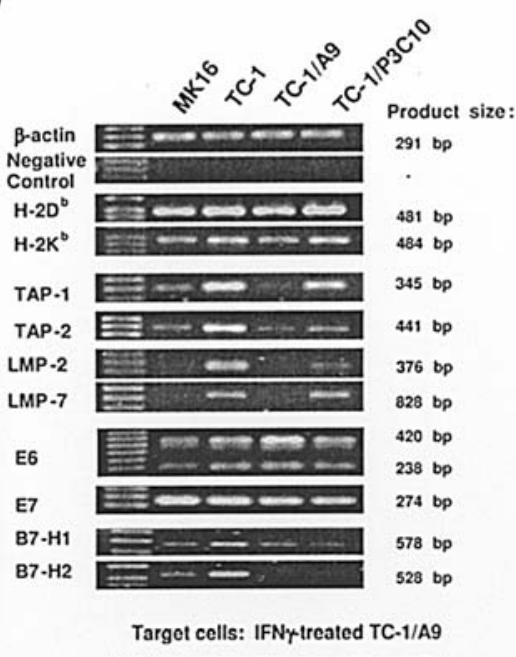

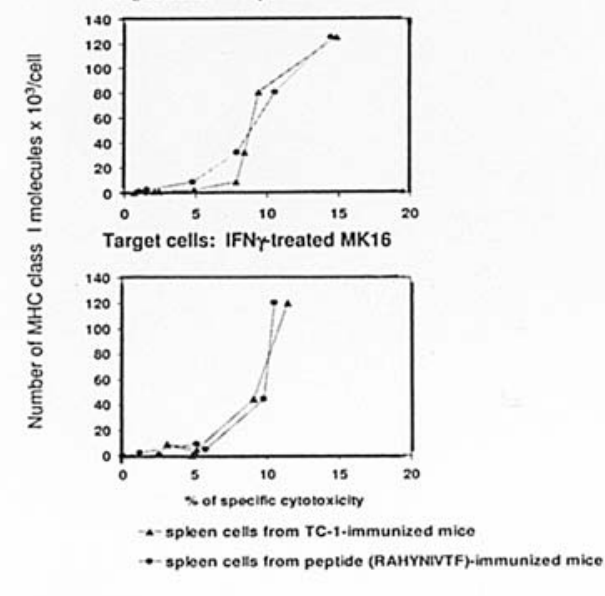

Figure 1. Phenotypic characterization of the tumour cell lines. (a) Distinct expression of MHC class I (H2-D ${ }^{\mathrm{b}}$ and $\mathrm{H} 2-\mathrm{K}^{\mathrm{b}}$ ), CD80 and CD54 molecules on the tumour cell lines was determined by flow cytometry. (b) Analysis of mRNA expression in the cell lines by RT-PCR revealed defects in the expression of TAP-1, TAP-2, LMP-2 and LMP-7 and different expression of B7-H1 and B7-H2 in distinct cell lines. Expression of E6 and E7 oncoproteins was proved in all cell lines. Samples with no addition of reverse transcriptase in the cDNA preparation step served as negative controls. (c) Peptide immunization. Mice (8 per group) were immunized with E7 $_{(49-57)}$ peptide or with control peptide $\mathrm{OVA}_{257-264}$ and challenged with TC-1/A9 or TC-1 cells. Controls were nonimmunized mice. Significant inhibition of the TC-1 but not of the TC-1/A9 tumour growth in E7 ${ }_{(49-57)}$-immunized mice compared to non-immunized and control peptide-immunized mice was recorded. The experiments were performed twice with similar results. (d) IFN $\gamma$-treated TC-1/A9 and MK16 cells were lysed by spleen cells from mice immunized both with TC-1 cells and with E7 $7_{(49-57)}$ peptide. The lysis efficacy is related to the number of the MHC class I molecules per cell.

complete RPMI-1640 medium supplemented with 0-50 ng/ml IFN $\gamma$ (40), and sets of cell populations with distinct surface expression of MHC class I molecules were obtained. The numbers of $\mathrm{MHC}$ class I molecules $\left(\mathrm{H} 2-\mathrm{D}^{\mathrm{b}}\right.$ and $\left.\mathrm{H} 2-\mathrm{K}^{\mathrm{b}}\right)$ were assessed by flow cytofluorometry using specific antibodies and a QuantiBRITE PE beads (Becton Dickinson) quantification kit for fluorescence quantitation. The cell populations characterized in respect to the level of MHC class I expression were subjected to ${ }^{51} \mathrm{Cr}$-microcytotoxicity assays (41) and the relationship between levels of MHC class I expression on target cells and their susceptibility to lysis were determined.

In vivo depletion studies. In vivo depletion of $\mathrm{NK} 1.1^{+}, \mathrm{CD} 4^{+}$ and $\mathrm{CD}^{+}$cells was performed using monoclonal antibodies PK 136, GK 1.5, and 2.43, respectively (40-44). To deplete the effector cells, $0.1 \mathrm{mg}$ of the antibody was i.p. injected into mice, during the first week injections were given three times and in the following two weeks, mice received injections once a week. Depletion was verified by the staining of spleen cells with labelled antibodies and FACS analysis. To efficiently diminish the number of NKT cells without activation of NK cells, $10 \mu \mathrm{g}$ of $B$-galactosylceramide (C12) (45) were repeatedly i.p. injected into mice at the same time-points as depletion antibodies.

Statistical analysis. For statistical analyses of the numbers of tumour takes in experimental and control groups, PetoWilcoxon and log-rank tests from NCSS, Number Cruncher Statistical System (Kaysville, UT) statistical package and the $\chi^{2}$ test were utilized. Analysis of variance by Newman-Keuls and Tukey-Kramer tests was used for statistical evaluation of the tumour growth curves. The differences between the curves were considered significant if the p-value was $<0.05$. For evaluation of chromium release microcytotoxic assays, the Student's t-test was utilized.

\section{Results}

Characterization of the cell lines. The tumour cell lines used in this study have been chacterized in detail (Fig. 1). The parental 
Immunization:

TC-1
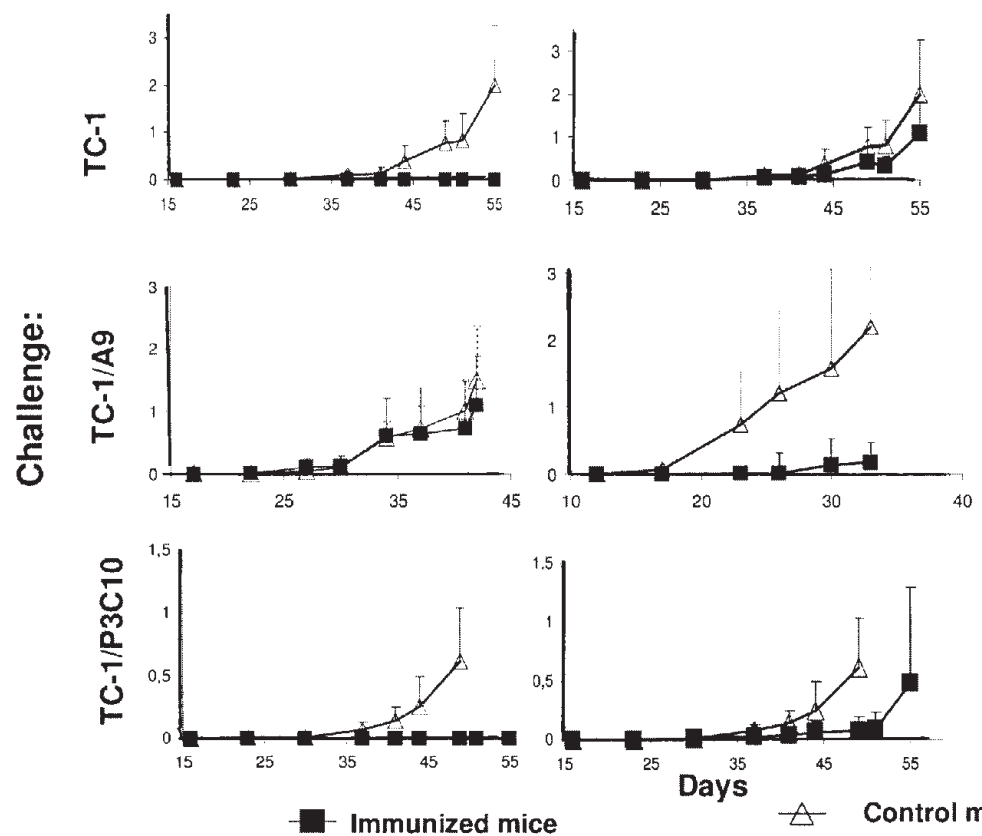

TC-1/P3C10
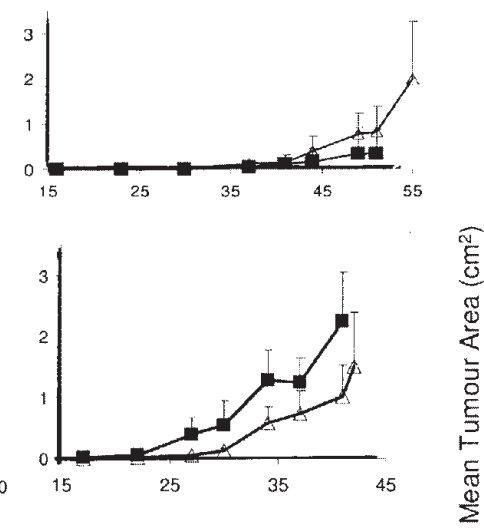

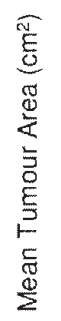

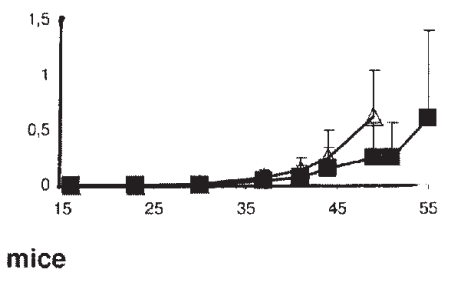

Figure 2. Immunologic crossreactivity between TC-1 cells and their MHC class I-deficient variants in vivo. Mice (7-8 per group) were immunized with TC-1, TC-1/A9 or TC-1/P3C10 tumour cells 5 weeks and 2 weeks prior to challenge (day 0) with 1x10 4 TC-1 cells, TC-1/P3C10 and TC-1/A9. All experiments were performed at least twice with similar results. Significant inhibition of the tumour growth in immunized mice compared to the controls (determined by NewmanKeuls and Tukey-Kramer tests, $\mathrm{p}<0.05)$ was recorded in mice immunized with the TC-1 cells and challenged with the TC-1 and the TC-1/P3C10 cells, in mice immunized with the TC-1/A9 cells and challenged with all tested cell lines and in mice immunized with the TC-1/P3C10 cells and challenged with the TC-1 and TC-1/P3C10 cells. Immunization with P3C10 did not block but significantly accelerated the growth of the TC-1/A9 tumours.

TC-1 cell line was MHC class I (H2-D ${ }^{\mathrm{b}}$ and $\left.\mathrm{H} 2-\mathrm{K}^{\mathrm{b}}\right)$-positive and subline TC-1/A9 MHC class I-negative, as determined by flow cytometry. The TC-1/P3C10 cell line displayed decreased but still detectable cell surface expression of MHC class I. The MK16 cell line was MHC class I-negative. Differences in the cell lines were also noted in the expression of other selected immunoactive molecules (CD80, CD54, B7-H1 and B7-H2). All cell lines expressed HPV16-derived E6 and E7 oncogenes (determined by RT-PCR), as well as $\mathrm{H}-2 \mathrm{~K}^{\mathrm{b}}$ and $\mathrm{H}-2 \mathrm{D}^{\mathrm{b}}$ mRNAs. Expression of genes representing the antigen-presenting machinery (APM), namely TAP1, TAP2, LMP2 and LMP7, was suppressed in MHC class Ideficient derivatives. All cell lines were MHC class II-, non-classic MHC class I Qa-1- and CD86-negative (data not shown). The efficacy of the specific immune response mediated by CTLs after immunization with the immunodominant peptide RAHYNIVTF against TC-1 but not TC-1/ A9 was demonstrated in vivo by immunization-challenge experiment. Finally, we have demonstrated that both TC-1/ A9 and MK16 cells can be lysed by specific CTLs after induction of MHC class I expression on their surface with IFN $\gamma$ and the efficacy of the lysis was related to the MHC class I expression level on the target cells. MK16 cells were less susceptible to the lysis compared to TC-1/A9 cells. Significant specific lysis of TC-1/A9 and MK16 cells by spleen cells from TC-1-immunized mice was observed in our experimental setting when the target cells expressed $\sim 10,000$ MHC I molecules and 45,000 molecules of MHC I per cell, respectively. Similarly, when the spleen cells from the mice immunized with the $\mathrm{E}_{49-57}$ peptide were used as effectors, the lysis became significant when TC-1/A9 cells and MK16 cells expressed 3000 and 10,000 molecules per cell, respectively.

Crossreactivity in vivo. The first goal was to assess the immunologic crossreactivity in vivo between parental MHC class I-positive TC-1 tumour cells and TC-1/A9 and TC-1/P3C10 cell lines (Fig. 2). We have demonstrated that immunization with MHC class I-deficient TC-1/A9 cells inhibited the growth of TC-1/A9 tumour while immunization with MHC class I-positive TC-1 and TC-1/P3C10 cells with reduced $\mathrm{MHC}$ class I expression did not result in protection against challenge with the TC-1/A9 MHC class I-deficient cell line. On the other hand, immunization with the MHC class I-deficient tumour cell lines inhibited the growth of the MHC class I-positive TC-1 tumours, albeit this protection was significantly weaker as compared to the TC-1 cell immunization. While immunization with the TC-1 cells prevented the growth of the TC- 1 tumours (on day 49, no mice out of 8 was tumour bearing compared to 7 out of 7 in the control group), immunization with the TC-1/A9 and the $\mathrm{TC} / 1 / \mathrm{P} 3 \mathrm{C} 10$ cell lines inhibited the tumour growth but did not influence the number of tumour takes. These results demonstrate that cross-priming, not dependent on MHC class I expression, is weaker than the direct priming. Immunization with the TC-1/P3C10 cells induced protective immunity against challenge with the same tumour cells as well as with the TC-1 cells, but not with MHC class I-negative TC-1/A9 cells. Furthermore, we assessed the crossreactivity between two 


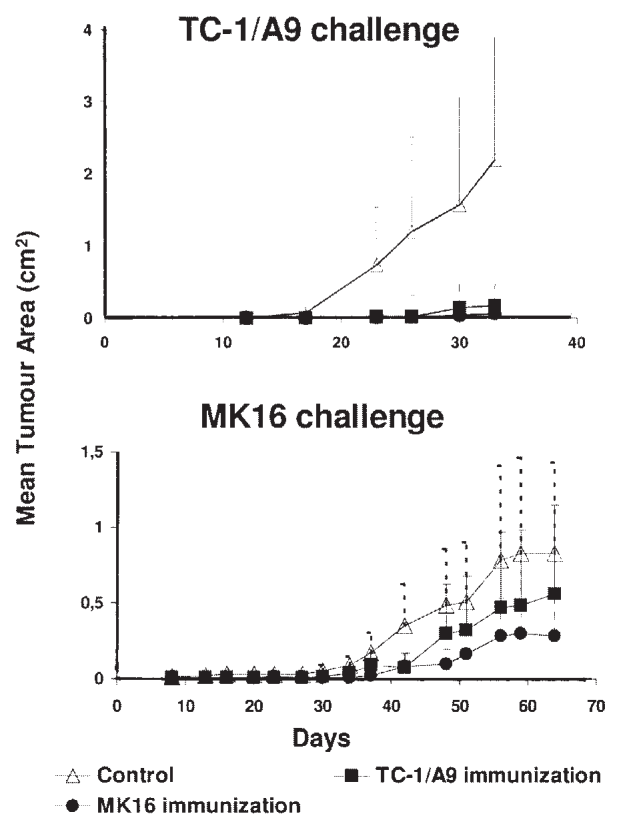

Figure 3. Immunologic crossreactivity between two MHC class I-negative tumour cell lines. Mice (8-10 per group) were immunized with TC-1/A9 or MK16 tumour cells 5 weeks and 2 weeks prior to challenge (day 0) and challenged with either $1 \times 10^{4} \mathrm{TC}-1 / \mathrm{A} 9$ or $1 \times 10^{5} \mathrm{MK} 16$ cells. Significant inhibition of the TC-1/A9 and the MK16 tumour growth compared to controls was observed in mice immunized with both cell lines (determined by Newman-Keuls and Tukey-Kramer tests, $\mathrm{p}<0.05)$. The experiments were performed three times with similar results. Control experiments demonstrated that MHC class I-deficient cell line RVP-3, which did not express E6/E7 oncoproteins, had no effect on the growth of TC-1/A9 cells (data not shown).

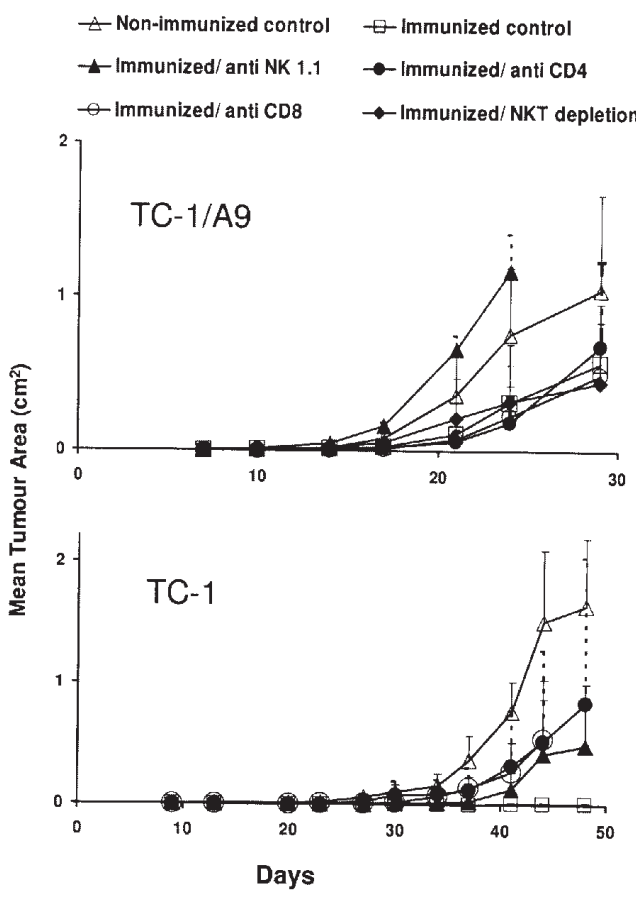

Figure 4. In vivo depletion of $\mathrm{NK} 1.1^{+}$cells but not of $\mathrm{CD}^{+}$or $\mathrm{CD}^{+}$cells accelerates TC-1/A9 tumour growth. The growth of the TC-1/A9 tumours in mice immunized with the TC-1/A9 cellular vaccine was significantly accelerated $(\mathrm{p}<0.05)$ after the depletion of $\mathrm{NK} 1.1^{+}$cells but not of $\mathrm{CD}^{+}$, $\mathrm{CD}^{+}$or NKT cells. In the control experiment, the growth of the TC-1 tumours was significantly accelerated after the depletion of $\mathrm{CD}^{+}$and $\mathrm{CD}^{+}$ cells. Each experimental group comprised at least 7 mice; the experiments were performed twice with similar results.
E6-, and E7-expressing cell lines TC-1/A9 and MK16, which were phenotypically MHC class I-negative, but of different origin and, moreover, they expressed distinct sets of selected immunomodulatory molecules (CD80, CD54, and B7-H1). Crossreactivity between these two cell lines was determined since the immunization with these tumour cell lines inhibited the growth of both TC-1/A9 and MK16 tumours (Fig. 3). Importantly, no immunity was induced by control MHC class Ideficient cell line RVP3. These results strongly suggest the significance of MHC class I expression in immunologic crossreactivity between various tumour cell lines of the same aetiology.

In vivo depletion experiments. The role of $\mathrm{CD} 4, \mathrm{CD} 8, \mathrm{NK}$ and NKT cells was assessed by in vivo depletion experiments. These experiments revealed that the growth of TC-1/A9 tumours in immunized, similarly to non-immunized mice, depended on NK cells; only the depletion of the NK1.1+ cells but not of the $\mathrm{CD}^{+}, \mathrm{CD} 8^{+}$or NKT cells significantly accelerated tumour growth (Fig. 4). In the control experiment, depletion of CD8 and CD4 cells, as expected, significantly accelerated TC-1 tumour growth in TC-1-immunized animals. These results indicate that even in the immunized mice the NK cells play a crucial role in the protection against the TC-1/A9 tumour challenge.

\section{Discussion}

We have demonstrated that immunization with a particular tumour cell line (MHC class I-positive or -deficient) induced immunity against the homologous tumours. These results suggest that immunization with cellular vaccines based on MHC class I-deficient tumour cells can be an effective tool against MHC class I-deficient tumours which escaped from the original immune response mediated mainly by $\mathrm{CD} 8^{+}$ CTLs. Such vaccines can also be effective against parental MHC class I-positive tumours due to activation of the CTLs by cross-priming. On the other hand, the lack of protective immunity against MHC class I-negative tumours after immunization with MHC class I-positive tumour cells indicate that effective MHC class I-unrestricted responses are not elicited by immunization with cellular vaccines based on the MHC class I-positive tumour cells. Notably, TC-1/P3C10 cells, with $\sim 10$-fold down-regulated MHC class I cell surface expression compared to the level on the TC-1 cells, did not elicit protective immunity against the challenge with TC-1/A9 cells and thus could be considered as 'MHC class I-positive'. The model used for our studies, the tumour cell sublines established from immunized animals, is relevant to the in vivo situation. On the other hand, it was not possible to exclude other factors which could, besides the MHC class I downmodulation, influence the mutual immunologic crossreactivity between two cell sublines. Therefore, the experiments analyzing the crossreactivity between the MK16 and the TC-1/A9 cell lines were performed. These two tumour cell lines were selected because they expressed the same tumour rejection antigens (E6 and E7), both were phenotypically MHC class Inegative and they were distinct in the expression of molecules important for interaction with T lymphocytes (CD54, CD80, B7-H2), an expression level of which could also contribute to 
the immune escape (46). Importantly, these cell lines were different in their origin (lungs vs. kidney). The crossreactivity between these two cell lines suggested a key role for the lack of MHC class I expression in the immune response and documented that immunization with a cellular vaccine based on the tumour cells deficient in MHC class I expression could elicit protective immune responses against tumours with a similar MHC class I status.

Distinct mechanisms of the immune responses against MHC class I-positive and -deficient tumours were further demonstrated by the in vivo depletion experiments. Our results document that the NK cells play an important role in the immune control of tumour growth not only in the treatmentnaïve but also in immunized animals, albeit the involvement of other mechanisms, e.g. those dependent on antibodies, cannot be excluded. The possible mechanisms by which immunization can influence the NK-mediated immunity are not clear and will be further investigated.

Unlike in the control immunization-challenge experiments with the TC-1 cells, in vivo depletion studies with mice immunized with and bearing TC-1/A9 tumours did not provide a role for the CTLs in the immune control of the tumour growth. Mechanisms leading to the MHC class I downmodulation, its reversibility and the level of downmodulation may be of particular importance in this context and CTLs could theoretically contribute to the anti-tumour immunity. MHC class I re-expression can be induced during experimental tumour growth by local IFN $\gamma$ secretion (40), making the originally MHC class I-negative tumour cells again sensitive to the CTLs. Further, MHC class I-deficient tumours with impaired antigen processing machinery can be targeted by CTL clones recognizing novel epitopes derived from proteins processed in APM-independent manners, presented in the context of the 'residual' MHC class I molecules and different from those being immunodominant on MHC class I-positive tumour cells (25). However, so far we have found no evidence regarding the role of $\mathrm{CD}^{+} \mathrm{CTL}$ inhibition of TC-1/A9 tumour growth in our experimental settings.

Finally, the $\mathrm{CD}^{+}$cell depletion did not significantly accelerate the tumour growth in the immunized mice. These results suggest either no role of $\mathrm{Th} \mathrm{CD}^{+}$cells in the immune responses or that the possible effect of $\mathrm{CD}^{+}{ }^{+} \mathrm{Th}$ cell depletion was eliminated by the effect of simultaneous $\mathrm{T}_{\text {reg }}\left(\mathrm{CD}^{+} / \mathrm{CD} 25^{+}\right)$ depletion.

Recently, prophylactic vaccines comprising structural proteins derived from the four most common high-risk HPV types preventing establishment of persistent virus infection have been developed $(47,48)$. On the other hand, no therapeutic vaccine is available against tumours expressing HPV viral oncoproteins. The data presented in this study are of clinical relevance since they document the possibility of vaccination against MHC class I-deficient tumours. Our results also strongly support the idea that the optimal immunotherapeutic strategy should vary according to the distinct MHC class I expression.

\section{Acknowledgements}

We are grateful to Dr T.C. Wu, who kindly provided the TC-1 cells, to Dr M. Smahel for making available the TC-1/A9 cells and to Dr Chien-Fu Hung for the TC-1/P3C10 cells. This study was supported by grant No. NR 7807-3 from the Grant Agency of the Ministry of Health of the Czech Republic, by the League against Cancer, Prague, by EU-FP6-NoE Clinigene Project No. 018933 and by grant No. AVOZ50520514 from the Academy of Sciences of the Czech Republic. The authors are grateful to Jasper Manning and Sarka Takacova for editorial help.

\section{References}

1. Keating PJ, Cromme FV, Duggan-Keen M, Snijders PJ, Walboomers JM, Hunter RD, Dyer PA and Stern PL: Frequency of down-regulation of individual HLA-A and -B alleles in cervical carcinomas in relation to TAP-1 expression. Br J Cancer 72: 405-411, 1995.

2. Cabrera T, Lopez-Nevot MA, Gaforio JJ, Ruiz-Cabello F and Garrido F: Analysis of HLA expression in human tumor tissues. Cancer Immunol Immunother 52: 1-9, 2003.

3. Koopman LA, Corver WE, van der Slik AR, Giphart MJ and Fleuren GJ: Multiple genetic alterations cause frequent and heterogeneous human histocompatibility leukocyte antigen class I loss in cervical cancer. J Exp Med 191: 961-976, 2000.

4. Tindle RW, Herd K, Doan T, Bryson G, Leggatt GR, Lambert P, Frazer IH and Street M: Non-specific down-regulation of CD8 ${ }^{+}$ T-cell responses in mice expressing human papillomavirus type 16 E7 oncoprotein from the keratin-14 promoter. J Virol 75: 5985-5997, 2001.

5. Garrido F, Ruiz-Cabello F, Cabrera T, Perez-Villar JJ, LopezBotet M, Duggan-Keen M and Stern PL: Implications for immunosurveillance of altered HLA class I phenotypes in human tumours. Immunol Today 18: 89-95, 1997.

6. Hicklin DJ, Marincola FM and Ferrone S: HLA class I antigen downregulation in human cancers: T-cell immunotherapy revives an old story. Mol Med Today 5: 178-186, 1999.

7. Bubenik J: MHC class I down-regulation: tumour escape from immune surveillance? (review). Int J Oncol 25: 487-491, 2004.

8. Chang CC, Campoli M and Ferrone S: HLA class I antigen expression in malignant cells: why does it not always correlate with CTL-mediated lysis? Curr Opin Immunol 16: 644-650, 2004.

9. Karre K, Ljunggren HG, Piontek G and Kiessling R: Selective rejection of $\mathrm{H}$-2-deficient lymphoma variants suggests alternative immune defence strategy. Nature 319: 675-678, 1986.

10. Lanier LL and Phillips JH: Inhibitory MHC class I receptors on NK cells and T cells. Immunol Today 17: 86-91, 1996.

11. Glas R, Sturmhofel K, Hammerling GJ, Karre K and Ljunggren HG: Restoration of a tumorigenic phenotype by beta 2-microglobulin transfection to EL-4 mutant cells. J Exp Med 175: 843-846, 1992.

12. Watson NF, Ramage JM, Madjd Z, Spendlove I, Ellis IO, Scholefield JH and Durrant LG: Immunosurveillance is active in colorectal cancer as downregulation but not complete loss of MHC class I expression correlates with a poor prognosis. Int $\mathbf{J}$ Cancer 118: 6-10, 2006.

13. Bubenik $\mathbf{J}$ and Vonka V: MHC class I status of tumours and design of immunotherapeutic strategies. Immunol Lett 90: 177-178, 2003.

14. Bubenik J: Tumour MHC class I downregulation and immunotherapy. Oncol Rep 10: 2005-2008, 2003.

15. Indrova M, Bubenik J, Mikyskova R, Vonka V, Smahel M, Zak R, Simova J, Bieblova J, Mendoza L and Jandlova T: Tumour-inhibitory and antimetastatic effects of IL-2 in mice carrying MHC class I- tumours of HPV16 origin. Int J Oncol 20: 643-646, 2002.

16. Reinis M, Simova J and Bubenik J: Inhibitory effects of unmethylated $\mathrm{CpG}$ oligodeoxynucleotides on MHC class Ideficient and -proficient HPV16-associated tumours. Int J Cancer 118: 1836-1842, 2006.

17. Levitsky HI, Lazenby A, Hayashi RJ and Pardoll DM: In vivo priming of two distinct antitumor effector populations: the role of MHC class I expression. J Exp Med 179: 1215-1224, 1994.

18. Bubenik J, Mikyskova R, Vonka V, Mendoza L, Simova J, Smahel $M$ and Indrova M: Interleukin-2 and dendritic cells as adjuvants for surgical therapy of tumours associated with human papillomavirus type 16. Vaccine 21: 891-896, 2003. 
19. Imboden M, Murphy KR, Rakhmilevich AL, Neal ZC, Xiang R, Reisfeld RA, Gillies SD and Sondel PM: The level of MHC class I expression on murine adenocarcinoma can change the antitumor effector mechanism of immunocytokine therapy. Cancer Res 61: 1500-1507, 2001

20. Neeley YC, McDonagh KT, Overwijk WW, Restifo NP and Sanda MG: Antigen-specific tumor vaccine efficacy in vivo against prostate cancer with low class I MHC requires competent class II MHC. Prostate 53: 183-191, 2002.

21. Cheng WF, Hung CF, Lin KY, Ling M, Juang J, He L, Lin CT and $\mathrm{Wu}$ TC: $\mathrm{CD}^{+} \mathrm{T}$ cells, $\mathrm{NK}$ cells and IFN-gamma are important for control of tumor with downregulated MHC class I expression by DNA vaccination. Gene Ther 10: 1311-1320, 2003.

22. Curti A, Parenza M and Colombo MP: Autologous and MHC class I-negative allogeneic tumor cells secreting IL-12 together cure disseminated A20 lymphoma. Blood 101: 568-575, 2003.

23. Pokorna D, Mackova J, Duskova M, Rittich S, Ludvikova V and Smahel M: Combined immunization with fusion genes of mutated E7 gene of human papillomavirus type 16 did not enhance antitumor effect. J Gene Med 7: 696-707, 2005.

24. Cheng WF, Hung CF, Lee CN, Su YN, Chang MC, He L, Wu TC, Chen CA and Hsieh CY: Naked RNA vaccine controls tumors with down-regulated MHC class I expression through NK cells and perforin-dependent pathways. Eur J Immunol 34: 1892-1900, 2004.

25. Van Hall T, Wolpert EZ, van Veelen P, Laban S, van der Veer M, Roseboom M, Bres S, Grufman P, De Ru A, Meiring H, De Jong A, Franken K, Teixeira A, Valentijn R, Drijfhout JW, Koning F, Camps M, Ossendorp F, Karre K, Ljunggren HG, Melief CJ and Offringa R: Selective cytotoxic T-lymphocyte targeting of tumor immune escape variants. Nat Med 12: 417-424, 2006.

26. Bubenik J: Animal models for development of therapeutic HPV16 vaccines. Int J Oncol 20: 207-212, 2002

27. Simova J, Mikyskova R, Vonka V, Bieblova J, Bubenik J and Jandlova T: MHC class $\mathrm{I}^{+}$and class I- HPV16-associated tumours expressing the $\mathrm{E} 7$ oncoprotein do not cross-react in immunization/ challenge experiments. Folia Biol 49: 230-234, 2003.

28. Garcia-Lora A, Martinez M, Algarra I, Gaforio JJ and Garrido F: MHC class I-deficient metastatic tumor variants immunoselected by $\mathrm{T}$ lymphocytes originate from the coordinated downregulation of APM components. Int J Cancer 106: 521-527, 2003.

29. Meissner M, Reichert TE, Kunkel M, Gooding W, Whiteside TL, Ferrone $\mathrm{S}$ and Seliger B: Defects in the human leukocyte antigen class I antigen processing machinery in head and neck squamous cell carcinoma: association with clinical outcome. Clin Cancer Res 11: 2552-2560, 2005.

30. Cromme FV, Airey J, Heemels MT, Ploegh HL, Keating PJ, Stern PL, Meijer CJ and Walboomers JM: Loss of transporter protein, encoded by the TAP-1 gene, is highly correlated with loss of HLA expression in cervical carcinomas. J Exp Med 179: 335-340, 1994

31. Ritz U, Momburg F, Pilch H, Huber C, Maeurer MJ and Seliger B: Deficient expression of components of the MHC class I antigen processing machinery in human cervical carcinoma. Int J Oncol 19: 1211-1220, 2001

32. Lin KY, Guarnieri FG, Staveley-O'Carroll KF, Levitsky HI, August JT, Pardoll DM and Wu TC: Treatment of established tumors with a novel vaccine that enhances major histocompatibility class II presentation of tumor antigen. Cancer Res 56: 21-26, 1996.

33. Smahel M, Sima P, Ludvikova V, Marinov I, Pokorna D and Vonka V: Immunisation with modified HPV 16 E7 genes against mouse oncogenic TC-1 cell sublines with downregulated expression of MHC class I molecules. Vaccine 21: 1125-1136, 2003.

34. Smahel M, Sobotkova E, Bubenik J, Simova J, Zak R, Ludvikova V, Hajkova R, Kovarik J, Jelinek F, Povysil C, Marinov $\mathrm{J}$ and Vonka V: Metastatic MHC class I-negative mouse cells derived by transformation with human papillomavirus type 16. Br J Cancer 84: 374-380, 2001.
35. Bubenik J, Koldovsky P, Svoboda J, Klement V and Dvorak R Induction of tumours in mice with three variants of rous sarcoma virus and studies on the immunobiology of these tumours. Folia Biol 13: 29-39, 1967

36. Feltkamp MC, Smits HL, Vierboom MP, Minnaar RP, De Jongh BM, Drijfhout JW, ter Schegget J, Melief CJ and Kast WM: Vaccination with cytotoxic T lymphocyte epitopecontaining peptide protects against a tumor induced by human papillomavirus type 16-transformed cells. Eur J Immunol 23: 2242-2249, 1993.

37. Yi AK and Krieg AM: CpG DNA rescue from anti-IgM-induced WEHI-231 B lymphoma apoptosis via modulation of I kappa B alpha and I kappa B beta and sustained activation of nuclear factor-kappa B/c-Rel. J Immunol 160: 1240-1245, 1998.

38. Kuchtey J, Chefalo PJ, Gray RC, Ramachandra L and Harding CV: Enhancement of dendritic cell antigen crosspresentation by CpG DNA involves type I IFN and stabilization of class I MHC mRNA. J Immunol 175: 2244-2251, 2005

39. Huang B, Zhao J, Li H, He K-L, Chen Y, Mayer L, Unkeless JC and Xiong H: Toll-like receptors on tumor cells facilitate evasion of immune surveillance. Cancer Res 65: 5009-5014, 2005

40. Mikyskova R, Bubenik J, Vonka V, Smahel M, Indrova M, Bieblova J, Simova J and Jandlova T: Immune escape phenotype of HPV 16-associated tumours: MHC class I expression changes during progression and therapy. Int J Oncol 26: 521-527, 2005.

41. Indrova M, Bubenik J, Mikyskova R, Mendoza L, Simova J, Bieblova J, Jandlova T, Jinoch P, Smahel M, Vonka V and Pajtasz-Piasecka E: Chemoimmunotherapy in mice carrying HPV16-associated, MHC class I+ and class I-tumours: effects of CBM-4A potentiated with IL-2, IL-12, GM-CSF and genetically modified tumour vaccines. Int J Oncol 22: 691-695, 2003.

42. Koo GC, Dumont FJ, Tutt M, Hackett J Jr and Kumar V: The NK-1.1(-) mouse: a model to study differentiation of murine NK cells. J Immunol 137: 3742-3747, 1986.

43. Dialynas DP, Quan ZS, Wall KA, Pierres A, Quintans J, Loken MR, Pierres M and Fitch FW: Characterization of the murine T cell surface molecule, designated L3T4, identified by monoclonal antibody GK1.5: similarity of L3T4 to the human Leu-3/T4 molecule. J Immunol 131: 2445-2451, 1983.

44. Sarmiento M, Glasebrook AL and Fitch FW: IgG or IgM monoclonal antibodies reactive with different determinants on the molecular complex bearing Lyt 2 antigen block T cell-mediated cytolysis in the absence of complement. J Immunol 125: $2665-2672,1980$

45. Ortaldo JR, Young HA, Winkler-Pickett RT, Bere EW Jr, Murphy WJ and Wiltrout RH: Dissociation of NKT stimulation, cytokine induction, and NK activation in vivo by the use of distinct TCR-binding ceramides. J Immunol 172: 943-953, 2005.

46. Tirapu I, Huarte E, Guiducci C, Arina A, Zaratiegui M, Murillo O, Gonzalez A, Berasain C, Berraondo P, Fortes P, Prieto J, Colombo MP, Chen L and Melero I: Low surface expression of B7-1 (CD80) is an immunoescape mechanism of colon carcinoma. Cancer Res 66: 2442-2450, 2006.

47. Koutsky LA, Ault KA, Wheeler CM, Brown DR, Barr E, Alvarez FB, Chiacchierini LM and Jansen KU: Proof of Principle Study Investigators. A controlled trial of a human papillomavirus type 16 vaccine. N Engl J Med 347: 1645-1651, 2002.

48. Villa LL, Costa RL, Petta CA, Andrade RP, Ault KA, Giuliano AR, Wheeler CM, Koutsky LA, Malm C, Lehtinen M, Skjeldestad FE, Olsson SE, Steinwall M, Brown DR, Kurman RJ, Ronnett BM, Stoler MH, Ferenczy A, Harper DM, Tamms GM, Yu J, Lupinacci L, Railkar R, Taddeo FJ, Jansen KU, Esser MT, Sings HL, Saah AJ and Barr E: Prophylactic quadrivalent human papillomavirus (types $6,11,16$, and 18) L1 virus-like particle vaccine in young women: a randomised double-blind placebocontrolled multicentre phase II efficacy trial. Lancet Oncol 6: 271-278, 2005. 